\title{
Characteristics of Modic changes in cervical kyphosis and their association with axial neck pain
}

\author{
Yonghui $A n^{1,2}$ \\ Jia $\mathrm{Li}^{1,2}$ \\ Yongqian $\mathrm{Li}^{1,2}$ \\ Yong Shen ${ }^{1,2}$ \\ 'Department of Orthopaedic \\ Surgery, The Third Hospital of Hebei \\ Medical University, Shijiazhuang, \\ People's Republic of China; ${ }^{2}$ The \\ Key Laboratory of Orthopedic \\ Biomechanics of Hebei Province, \\ The Third Hospital of Hebei Medical \\ University, Shijiazhuang, People's \\ Republic of China
}

This article was published in the following Dove Press journal: Journal of Pain Research

14 July 2017

Number of times this article has been viewed

Background: The purpose of this study was to evaluate characteristics of Modic changes in cervical kyphosis (CK) and their association with axial neck pain.

Methods: Study participants included 286 asymptomatic or symptomatic patients with CK (mean age $=54.2 \pm 12.2$ years) who were consecutively enrolled from March 2009 to October 2015. Clinical and radiographic evaluations were performed at a university outpatient department. CK was classified as global type, reverse sigmoid type, or sigmoid type.

Results: There were 138 participants with global type CK, 103 with reverse sigmoid type CK, and 45 with sigmoid type CK. Of the 286 participants, 102 had Modic changes (Modic-1 in 38 segments and Modic-2 in 75 segments). Spinal cord compression grade and disc degeneration occurred more frequently in the group with axial neck pain compared to the group without pain. Angular motion was decreased in those with axial neck pain (mean \pm standard deviation [SD] $7.8^{\circ} \pm 4.6^{\circ}$ ) compared to those who were asymptomatic (mean \pm SD $8.9^{\circ} \pm 5.1^{\circ} ; P<0.001$ ). In multivariate logistic regression analysis, Modic changes were associated with axial neck pain (odds ratio $=5.356 ; 95 \%$ confidence interval $=1.314-12.800 ; P<0.001$ ).

Conclusion: Modic changes occur most commonly in association with CK global type and less commonly with reverse sigmoid type and sigmoid type. Modic changes are associated with axial neck pain in patients with $\mathrm{CK}$.

Keywords: cervical kyphosis, axial neck pain, Modic change, kinematic analysis, magnetic resonance imaging

\section{Introduction}

Modic changes, degenerative changes to vertebral endplate and subchondral bone marrow that can be detected by magnetic resonance imaging (MRI), are strongly associated with degenerative disc disease. Three types of Modic changes can be described based on their histopathology. Modic-1 changes reflect bone marrow edema and inflammation. Modic-2 changes manifest as bone marrow ischemia with conversion of normal red hematopoietic bone marrow to yellow fatty marrow. Modic-3 changes indicate subchondral bone sclerosis. ${ }^{1,2}$ Many studies of disc degeneration and low back pain suggest strong associations between pain and Modic changes. ${ }^{3-7}$

Axial neck pain, which is frequently reported by patients as neck pain, stiffness, or dullness, may be caused by several underlying conditions. Degenerative disc disease is also believed to be a significant risk factor for axial neck pain. Previous studies suggest that lesions to the discs, facet joints, and neck muscles may contribute to symptoms. ${ }^{8-10}$ Furthermore, Modic changes are often observed in people with axial neck pain. ${ }^{9}$
Department of Orthopaedic Surgery, The Third Hospital of Hebei Medical University, 139 Ziqiang Road, Shijiazhuang, 05005I, People's Republic of China

Tel +8631 I 88602016

Fax +8631188602015

Email ljlyqbwin2010@yeah.net 
Cervical kyphosis (CK) affects spinal kinematics and causes spinal cord compression. It is also an important risk factor for accelerating intervertebral disc degeneration. ${ }^{13}$ Patients with $\mathrm{CK}$ are more likely to develop neck pain and neurologic deficits. ${ }^{11-13}$ It is thought that cervical Modic changes are related to axial neck pain in patients with $\mathrm{CK}$. The purpose of this study was to evaluate the characteristics of Modic changes in patients with $\mathrm{CK}$ and their association with axial neck pain.

\section{Methods}

This study retrospectively evaluated images from 286 asymptomatic or symptomatic patients with CK (mean age $=54.2 \pm 12.2$ years; range $=30-70$ years) who were consecutively enrolled from March 2009 to October 2015. Patients were eligible for study inclusion if they had or did not have chronic, nonspecific, axial neck pain of at least 3 months duration. To determine whether axial neck pain was associated with Modic changes or CK, we obtained MRI scans for 160 asymptomatic patients who underwent physical examination at a university hospital during the study period. Exclusion criteria were trauma, fracture, infection, rheumatic disease, tumor, and history of cervical surgery. ${ }^{14-16}$

The cervical discs from $\mathrm{C} 2-\mathrm{C} 3$ to $\mathrm{C} 6-\mathrm{C} 7$ were retrospectively evaluated for all study participants. This study was approved by the Regional Ethics Committee of The Third Hospital of Hebei Medical University, and all patients provided written informed consent. The study was conducted in accordance with approved hospital guidelines.

Radiographic evaluation included X-ray imaging, computed tomography (CT), and MRI of the cervical spine. Two experienced, independent radiologists without knowledge of the clinical outcomes assessed the radiographs. Differences that arose in radiographic interpretation were reconciled by a third, experienced radiologist. Spinal cord MRIs were obtained using a spin echo sequence system for T1-weighted images (T1WIs) and a fast spin echo sequence system for T2-weighted images (T2WIs). A cervical coil was used. Modic changes were classified as Modic-1, Modic-2, Modic3 , and no change. Pfirrmann criteria were used to classify disc degeneration into one of the five grades based on T2WI findings. ${ }^{17}$ Angular motion was defined as the intervertebral angle difference between two vertebrae from flexion to extension, as determined by X-ray imaging. Spinal cord compression was graded using the modified method of Hayashi et $\mathrm{al}^{18}$ : obliteration of the subarachnoid space in the presence of disc herniation, osteophyte formation, or hypertrophy of the ligamentum flavum.
Sagittal alignment of the cervical spine (SACS) was defined using the modified method of Ohara et al, ${ }^{19}$ wherein $\mathrm{CK}$ is classified into three types using sagittal X-ray imaging. Global type $\mathrm{CK}$ has all centroids posterior to the $\mathrm{C} 2-\mathrm{C} 7$ centroid line, and the distance from at least one centroid to the line is $\geq 2 \mathrm{~mm}$ (Figure 1). In the reverse sigmoid type, at least one upper cervical centroid is posterior to and at least one lower cervical centroid is anterior to the $\mathrm{C} 2-\mathrm{C} 7$ centroid line, and the distance between the $\mathrm{C} 2-\mathrm{C} 7$ centroid line and at least one centroid is $\geq 2 \mathrm{~mm}$ (Figure 2). For sigmoid type, at least one upper cervical centroid is anterior to and at least one lower cervical centroid is posterior to the $\mathrm{C} 2-\mathrm{C} 7$ centroid line, and the distance from the $\mathrm{C} 2-\mathrm{C} 7$ centroid line to at least one centroid is $\geq 2 \mathrm{~mm}$ (Figure 3 ). ${ }^{13}$

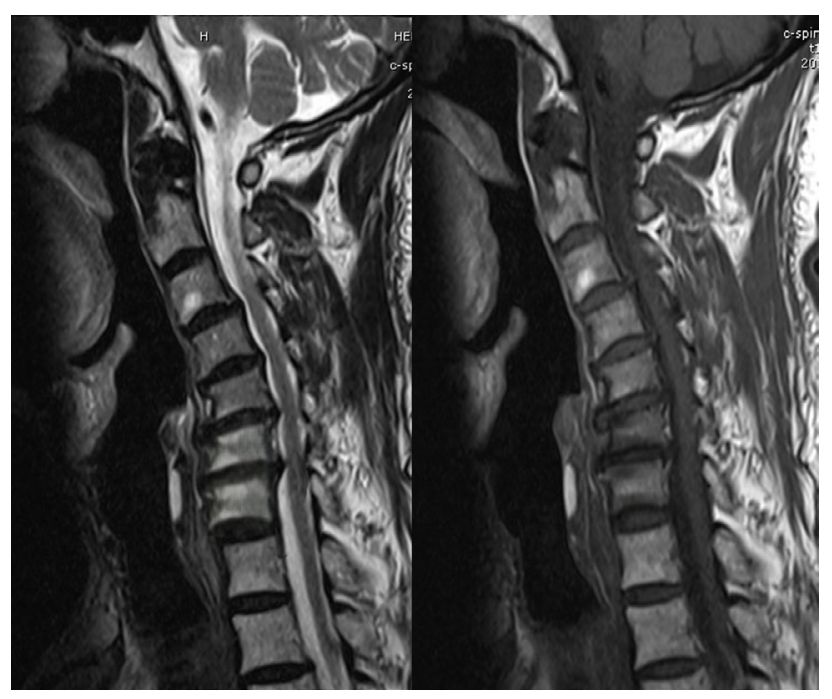

Figure I Global type cervical kyphosis with Modic-I changes in C5-C6 and C6-C7.

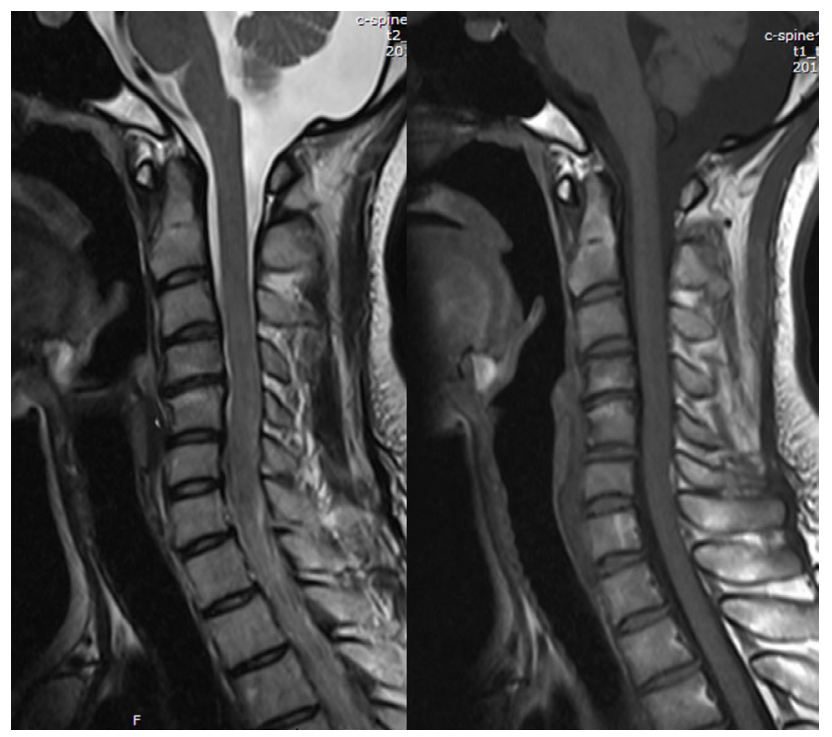

Figure 2 Reverse sigmoid type cervical kyphosis with Modic-2 changes in C4-C5. 


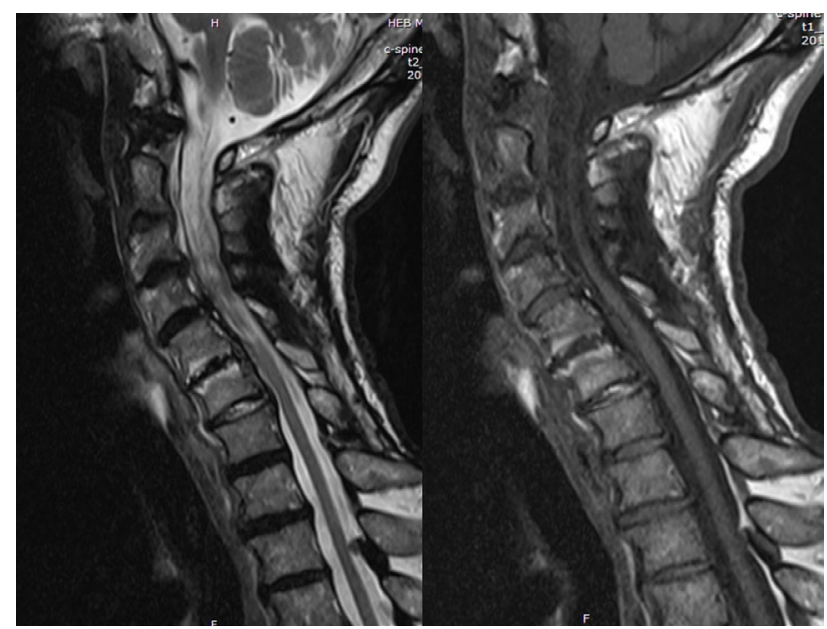

Figure 3 Sigmoid type cervical kyphosis with Modic-2 changes in C5-C6.

\section{Statistical analysis}

SPSS software (Version 19.0; Chicago, IL, USA) was used for statistical analyses. The independent $t$-test or Chi-square test was used to identify significant differences between groups. Relevant factors for axial neck pain were analyzed using a multivariate logistic regression model. In all analyses, significance was defined as a $P$-value of $<0.05$. Results are presented as mean \pm standard deviation. The kappa statistic was used to evaluate the interobserver and intraobserver reliabilities of Modic changes based on MRI findings. Cohen's kappa coefficients ${ }^{13,14}$ were used to determine the reliability of Modic changes in this study: $0.81-1.0$, excellent; $0.61-0.80$, substantial; $0.41-0.60$, moderate; $0.21-0.40$, fair; $0.0-0.20$, slight; $<0.0$, poor.

\section{Results}

Overall, there were 138 patients in the global type group, 103 patients in the reverse sigmoid type group, and 45 patients in the sigmoid type group. Of the 286 participants with 1430 segments, 102 patients had Modic changes (Modic-1 in 38 segments and Modic-2 in 75 segments). Modic-3 changes and mixed types were not found in this study. There were no differences in Modic changes between patients with global-, reverse sigmoid-, and sigmoid type CK ( $P=0.341)$. However, Modic changes occurred more often in patients with global type CK compared to other CK types, with Modic- 2 changes being the most frequent (but nonsignificant) Modic changes in the global type group (Table 1). Intraobserver agreement

Table I Comparison of Modic changes in each group

\begin{tabular}{llll}
\hline $\begin{array}{l}\text { Modic } \\
\text { types }\end{array}$ & Global type & Reverse sigmoid type & Sigmoid type \\
\hline Modic-1 & 23 & 12 & 3 \\
Modic-2 & 36 & 27 & 12 \\
\hline
\end{tabular}

with Modic classification was excellent (weighted kappa $=0.81$ ), and interobserver agreement with Modic classification was substantial (weighted kappa $=0.72$ ).

Participants with axial neck pain experienced more severe disc degeneration $(P<0.001)$ and worse spinal cord compression compared to those who were asymptomatic $(P=0.023)$. Furthermore, angular motion was decreased in the axial neck pain group compared to the asymptomatic group $(P<0.001)$.

Using axial neck pain as a dependent variable, multivariate logistic regression was used to explore risk factors. Univariate analysis results for participants with and without axial neck pain are shown in Table 2. Disc degeneration grade, Modic changes, angular motion, and spinal cord compression grade were all significant in univariate analyses at the $P<0.1$ level; these variables were analyzed as dependent variables using a forward stepwise method. In the stepwise analysis, Modic changes were associated with axial neck pain (odds ratio $=5.356 ; 95 \% \mathrm{CI}=1.314-12.800 ; P<0.001)$. For patients with $\mathrm{CK}$, the highest relative risk for axial neck pain was conferred by the presence of Modic changes. Age, CK type, spinal cord compression grade, angular motion, and disc degeneration were not associated with axial neck pain.

\section{Discussion}

Previous studies have demonstrated associations between Modic changes and low back symptoms ${ }^{20,21}$ and between Modic changes and lumbar spine kinematics. ${ }^{19,22-24}$ To the best of our knowledge, no previous study has shown a relationship between Modic changes and axial neck pain in CK. Furthermore, our study shows that different CK types may affect cervical spine characteristics and segmental spinal

Table 2 Comparison between axial neck pain group and nonaxial neck pain group in terms of radiographic evaluation

\begin{tabular}{|c|c|c|c|}
\hline Characteristics & $\begin{array}{l}\text { Axial neck } \\
\text { pain }\end{array}$ & $\begin{array}{l}\text { Nonaxial neck } \\
\text { pain }\end{array}$ & $P$ \\
\hline Age (years), mean $\pm S D$ & $56.3 \pm 11.5$ & $50.5 \pm 15.3$ & 0.327 \\
\hline Gender, (M/F), n & $68 / 59$ & $72 / 87$ & 0.165 \\
\hline BMI $\left(\mathrm{kg} / \mathrm{m}^{2}\right)$, mean $\pm \mathrm{SD}$ & $25.9 \pm 4.5$ & $24.5 \pm 4.9$ & 0.632 \\
\hline Diabetes mellitus, n (\%) & $21(16.5)$ & $28(17.6)$ & 0.811 \\
\hline Type of CK, n & & & 0.907 \\
\hline Global type & 63 & 75 & \\
\hline Reverse sigmoid type & 45 & 58 & \\
\hline Sigmoid & 19 & 26 & \\
\hline Modic changes, n (\%) & $70(55.1)$ & $32(20.1)$ & 0.000 \\
\hline $\begin{array}{l}\text { Disc degeneration grade, } \\
\text { mean } \pm \text { SD }\end{array}$ & $4.5 \pm 0.6$ & $3.3 \pm 0.5$ & 0.000 \\
\hline $\begin{array}{l}\text { Spinal cord compression } \\
\text { grade, mean } \pm \text { SD }\end{array}$ & $1.9 \pm 1.2$ & $1.4 \pm 1.1$ & 0.023 \\
\hline $\begin{array}{l}\text { Angular motion }\left({ }^{\circ}\right) \\
\text { mean } \pm \mathrm{SD}\end{array}$ & $7.8 \pm 4.6$ & $8.9 \pm 5.1$ & 0.000 \\
\hline
\end{tabular}

Abbreviations: BMI, body mass index; CK, cervical kyphosis; M, male; F, female; $\mathrm{SD}$, standard deviation. 
cord compression. Our multivariate analysis showed that Modic changes were related to axial neck pain in patients with CK and that a distribution of Modic changes exists among patients with various $\mathrm{CK}$ types. Our study also showed increased spinal cord compression grade, decreased angular motion, and increased disc degeneration in patients with $\mathrm{CK}$ and Modic changes compared to patients with $\mathrm{CK}$ and non-Modic changes.

The prevalence of cervical spine Modic changes in patients varies from 4.5 to $13.9 \%$, with Modic- 2 changes occurring most frequently and Modic-3 and mixed type changes being relatively rare. However, the prevalence distribution of Modic changes is debated, with some authors reporting Modic-1 changes to be most common $(16 \%)^{25}$ and others reporting Modic-2 changes to be the most common. ${ }^{9,26,27}$ In our study, the prevalence of Modic changes for asymptomatic and symptomatic persons with CK was $35.7 \%$. Moreover, no differences were found with respect to Modic changes for participants with global-, reverse sigmoid-, and sigmoid type CK. Thus, Modic changes were found most commonly among patients with global type CK.

Because this study used X-rays obtained in the upright position but CT and MRI obtained in the supine position, differences in SACS may be due to the differing effect of gravity on the spine in these two positions. However, there was a strong correlation for cervical sagittal alignment parameters between imaging modalities. ${ }^{28}$

CK affects range of motion and spinal cord compression, ${ }^{13}$ with greater $\mathrm{CK}$ associated with increased risk of axial neck pain. ${ }^{29-31}$ Spinal cord compression occurs along the transitional and apical zones of $\mathrm{CK}^{13}$ during extension and flexion. This compression with movement may explain the associated neurologic deficits and axial neck pain. Studies have shown that angular motion and spinal cord compression in patients with $\mathrm{CK}$ are like those found in patients with degenerated discs, ${ }^{31,32}$ with motion characteristics being dependent on CK type. An alternative explanation for decreased angular motion and spinal cord compression in patients with $\mathrm{CK}$ is the effect of Modic changes themselves. Segments affected by Modic changes tend to lose mobility and angular motion in patients with severe disc degeneration.

Modic changes occur most often at the C3-C4 through C5-C6 levels, ${ }^{25-27}$ and spinal cord compression caused by $\mathrm{CK}$ is increased in extension and decreased in flexion and the neutral position at the C4-C5 and C5-C6 levels. Miyazaki et al showed that angular motion at C4-C5 and C5-C6 was decreased in the presence of disc degeneration. ${ }^{31,32}$ As in our study, Hayashi et $\mathrm{al}^{18}$ showed that cervical spines with Modic changes had decreased angular motion and more severe disc degeneration compared to those without Modic changes. Mann et $\mathrm{al}^{27}$ likewise found a relationship between Modic changes and disc herniation at the same level. In our study, patients with $\mathrm{CK}$ and non-Modic changes had increased disc degeneration grade and spinal cord compression with decreased angular motion.

Modic changes have also been associated with disc degeneration, presence of low back pain, and low back pain severity. ${ }^{4,23}$ Although our study showed that Modic changes were associated with axial neck pain in patients with $\mathrm{CK}$, multivariate logistic regression analysis showed that $\mathrm{CK}$ type, angular motion, spinal cord compression, and disc degeneration were not risk factors for patients with axial neck pain and CK.

\section{Limitations}

The present study has some limitations. Firstly, the lack of a control group (eg, cervical lordosis group) does not allow us to compare axial neck pain between those with CK and those with other cervical disease. Because we sampled patients consecutively, we could not control for variables in patients with $\mathrm{CK}$ such as symptom duration. Thus, selection bias may exist. Lastly, Modic changes to the cervical spine are dynamic and different types may convert over time. Therefore, prospective, large-scale, follow-up studies are needed to determine the relationship between $\mathrm{CK}$ and axial neck pain.

\section{Conclusion}

Modic changes are most common in patients with global type $\mathrm{CK}$, followed by reverse sigmoid type $\mathrm{CK}$ and sigmoid type CK. Although Modic changes are associated with axial neck pain in patients with CK, CK type does not appear to influence axial neck pain.

\section{Author contributions}

All authors contributed toward data analysis, drafting and critically revising the paper, gave final approval of the version to be published, and agree to be accountable for all aspects of the work.

\section{Disclosure}

The authors report no conflicts of interest in this work.

\section{References}

1. Modic MT, Steinberg PM, Ross JS, Masaryk TJ, Carter JR. Degenerative disk disease: assessment of changes in vertebral body marrow with MR imaging. Radiology. 1988;166(1 Pt 1):193-199.

2. Modic MT, Masaryk TJ, Ross JS, Carter JR. Imaging of degenerative disk disease. Radiology. 1988;168:177-186. 
3. Albert HB, Briggs AM, Kent P, Byrhagen A, Hansen C, Kjaergaard $\mathrm{K}$. The prevalence of MRI-defined spinal pathoanatomies and their association with modic changes in individuals seeking care for low back pain. Eur Spine J. 2011;20(8):1355-1362.

4. Mok FP, Samartzis D, Karppinen J, Fong DY, Luk KD, Cheung KM. Modic changes of the lumbar spine: prevalence, risk factors, and association with disc degeneration and low back pain in a large-scale population-based cohort. Spine J. 2016;16(1):32-41.

5. Jensen RK, Leboeuf-Yde C, Wedderkopp N, Sorensen JS, Jensen TS, Manniche C. Is the development of Modic changes associated with clinical symptoms? A 14-month cohort study with MRI. Eur Spine J. 2012;21(11): 2271-2279.

6. Kovacs FM, Arana E, Royuela A, et al. Disc degeneration and chronic low back pain: an association which becomes nonsignificant when endplate changes and disc contour are taken into account. Neuroradiology. 2014;56(1):25-33.

7. Jensen OK, Nielsen CV, Sørensen JS, Stengaard-Pedersen K. Type 1 Modic changes was a significant risk factor for 1-year outcome in sicklisted low back pain patients: a nested cohort study using magnetic resonance imaging of the lumbar spine. Spine $J .2014 ; 14(11): 2568-2581$.

8. Wagner SC, Formby PM, Kang DG, et al. Persistent axial neck pain after cervical disc arthroplasty: a radiographic analysis. Spine $J$. 2016;16(7):851-856

9. Sheng-yun L, Letu S, Jian C, et al. Comparison of modic changes in the lumbar and cervical spine, in 3167 patients with and without spinal pain. PLoS One. 2014;9(12):e114993.

10. Kawakami M, Tamaki T, Yoshida M, Hayashi N, Ando M, Yamada H. Axial symptoms and cervical alignments after cervical anterior spinal fusion for patients with cervical myelopathy. J Spinal Disord. 1999;12(1):50-56.

11. Chavanne A, Pettigrew DB, Holtz JR, Dollin N, Kuntz C 4th. Spinal cord intramedullary pressure in cervical kyphotic deformity: a cadaveric study. Spine. 2011;36(20):1619-1626.

12. Takeshita K, Murakami M, Kobayashi A, Nakamura C. Relationship between cervical curvature index (Ishihara) and cervical spine angle (C2-7). J Orthop Sci. 2001;6:223-226.

13. Ruangchainikom M, Daubs MD, Suzuki A, et al. Effect of cervical kyphotic deformity type on the motion characteristics and dynamic spinal cord compression. Spine (Phila Pa 1976). 2014;39(12):932-938.

14. Seo HJ, Kim SY, Lee YJ, et al. A newly developed tool for classifying study designs in systematic reviews of interventions and exposures showed substantial reliability and validity. J Clin Epidemiol. 2016;70: 200-205.

15. Dekkers OM, Egger M, Altman DG, Vandenbroucke JP. Distinguishing case series from cohort studies. Ann Intern Med. 2012;156(1 pt 1):37-40.

16. Esene IN, Ngu J, El Zoghby M, et al. Case series and descriptive cohort studies in neurosurgery: the confusion and solution. Childs Nerv Syst. 2014;30(8):1321-1332.

17. Pfirrmann CW, Metzdorf A, Zanetti M, Hodler J, Boos N. Magnetic resonance classification of lumbar intervertebral disc degeneration. Spine (Phila Pa 1976). 2001;26:1873-1878.
18. Hayashi T, Daubs MD, Suzuki A, Phan K, Shiba K, Wang JC. Effect of Modic changes on spinal canal stenosis and segmental motion in cervical spine. Eur Spine J. 2014;23(8):1737-1742.

19. Ohara A, Miyamoto K, Naganawa T, Matsumoto K, Shimizu K. Reliabilities of and correlations among five standard methods of assessing the sagittal alignment of the cervical spine. Spine (Phila Pa 1976). 2006;31(22):2585-2591.

20. Bechara BP, Agarwal V, Boardman J, et al. Correlation of pain with objective quantification of magnetic resonance images in older adults with chronic low back pain. Spine (Phila Pa 1976). 2014;39(6): 469-475.

21. Samartzis D, Karppinen J, Mok F, Fong DY, Luk KD, Cheung KM. A population-based study of juvenile disc degeneration and its association with overweight and obesity, low back pain, and diminished functional status. J Bone Joint Surg Am. 2011;93:662-670.

22. Hayashi T, Daubs MD, Suzuki A, et al. Motion characteristics and related factors of Modic changes in the lumbar spine. $J$ Neurosurg Spine. 2015;22(5):511-517.

23. Järvinen J, Karppinen J, Niinimäki J, et al. Association between changes in lumbar Modic changes and low back symptoms over a two-year period. BMC Musculoskelet Disord. 2015;16:98.

24. Määttä JH, Wadge S, MacGregor A, Karppinen J, Williams FM. Vertebral endplate (Modic) change is an independent risk factor for episodes of severe and disabling low back pain. Spine (Phila Pa 1976). 2015;40:1187-1193.

25. Peterson CK, Humphreys BK, Pringle TC. Prevalence of Modic degenerative marrow changes in the cervical spine. $J$ Manipulative Physiol Ther. 2007;30(1):5-10.

26. Matsumoto M, Okada E, Ichihara D, et al. Modic changes in the cervical spine: prospective 10-year follow-up study in asymptomatic subjects. J Bone Joint Surg Br. 2012;94(5):678-683.

27. Mann E, Peterson CK, Hodler J. Degenerative marrow (modic) changes on cervical spine magnetic resonance imaging scans: prevalence, interand intra-examiner reliability and link to disc herniation. Spine (Phila Pa 1976). 2011;36(14):1081-1085.

28. Jun HS, Chang IB, Song JH, et al. Is it possible to evaluate the parameters of cervical sagittal alignment on cervical computed tomographic scans? Spine (Phila Pa 1976). 2014;39(10):E630-E636.

29. Masini M, Maranhao V. Experimental determination of the effect of progressive sharp-angle spinal deformity on the spinal cord. Eur Spine J. 1997;6(2):89-92.

30. Ohshio I, Hatayama A, Kaneda K, Takahara M, Nagashima K. Correlation between histopathologic features and magnetic resonance images of spinal cord lesions. Spine(Phila Pa 1976). 1993;18:1140-1149.

31. Miyazaki M, Hymanson HJ, Morishita Y, et al. Kinematic analysis of the relationship between sagittal alignment and disc degeneration in the cervical spine. Spine (Phila Pa 1976). 2008;33(23):870-876.

32. Miyazaki M, Hong SW, Yoon SH, et al. Kinematic analysis of the relationship between the grade of disc degeneration and motion unit of the cervical spine. Spine (Phila Pa 1976). 2008;33(2):187-193.
Journal of Pain Research

\section{Publish your work in this journal}

The Journal of Pain Research is an international, peer reviewed, open access, online journal that welcomes laboratory and clinical findings in the fields of pain research and the prevention and management of pain. Original research, reviews, symposium reports, hypothesis formation and commentaries are all considered for publication.
The manuscript management system is completely online and includes a very quick and fair peer-review system, which is all easy to use. Visit http://www.dovepress.com/testimonials.php to read real quotes from published authors. 